\title{
Кольский центр коллективного пользования (ЦКП) геохронологических и геохимических исследований: основные достижения
}

\author{
Баянова Т.Б., Кудряшов Н.М., Серов П.А., Стешенко Е.Н., Кунаккузин Е.Л., Каменский И.Л., \\ Елизаров Д.В.
}

Геологический институт КНЦ РАН, Anamuты, tamara@geoksc.apatity.ru

\begin{abstract}
Аннотация. Приведены новые U-Pb геохронологические возрастные данные для циркона из хадейпалеопротерозойских пород континентальной коры Центрально-Кольского мегаблока, а также для неоархейских крупных месторождений золота зеленокаменного пояса Колмозеро-Воронья. Представлены новые U-Pb возрастные данные по бадделеиту из месторождений неоархей-палеопротерозойского возраста: Кировогорского, Цагинского, Силлиньярви, а также Мончегорского, Федорово-Панского и Имандровского рудных районов. На океанической коре сформированы месторождения с U-Pb возрастами по бадделеиту палеопротерозоя: Падостунровское, Печенга и Колвицкое. Для палеозоя приведены U-Pb данные по бадделеиту крупнейших месторождений Ковдора, Себльявра и Вуориярви. Изотопно-геохимические величины $-\mathrm{T}_{\mathrm{DM}}$, $\varepsilon \mathrm{Nd}, \mathrm{I}_{\mathrm{Sr}}$ и $\mathrm{He}^{3} / \mathrm{He}^{4}$ измерены для пород и рудных минералов в интервале от 3.7 млрд. лет до 380 млн. лет. Приводится корреляция суперконтинентальных циклов, отражающая формирование месторождений в обширных изверженных провинциях (LIP) и распад суперконтинентов в истории развития Земли.
\end{abstract}

Ключевые слова: $\mathrm{U}-\mathrm{Pb}$, циркон, бадделеит, $\mathrm{T}_{\mathrm{DM}}$, $\mathrm{Nd}$, $\mathrm{I}_{\mathrm{Sr}}$, рудные месторождения, $\mathrm{He}^{3} / \mathrm{He}^{4}$.

\section{Kola Collective Use Centre (Cuc) for geochronological and geochemical studies: main achievements}

\author{
Bayanova T.B., Kudryashov N.M., Serov P.A., Steshenko E.N., Kunakkuzin E.L., Kamensky I.L., \\ Elizarov D.V. \\ Geological institute KSC RAS, Apatity, tamara@geoksc.apatity.ru
}

\begin{abstract}
The paper provides new U-Pb geochronological data on zircon in Hadean-Paleoproterozoic rocks from the continental crust in the Central Kola megablock and major Neoarchaean gold deposits in the KolmozeroVoronya greenstone belt. The paper presents new U-Pb isotope data on baddeleyite from Neoarchaean-Paleoproterozoic complex deposits, i.e. the Kirovogorskoye, Tsaga, Sillinjarvi deposits, as well as the Monchegorsk, Fedorovo-Pansky and Imandra ore areas. The Paleoproterozoic deposits of Pados Tundra, Pechenga and Kolvitsa formed on the oceanic crust. Their ages have been U-Pb-dated on baddeleyite. U-Pb isochrones on baddeleyite are provided for major Paleozoic deposits of Kovdor, Seblyavr and Vuorijarvi. Isotope-geochemical values of $\mathrm{T}_{\mathrm{DM}}, \varepsilon \mathrm{Nd}, \mathrm{I}_{\mathrm{Sr}}$ and $\mathrm{He}^{3} / \mathrm{He}^{4}$ have been estimated for rocks and ore elements in the time range of $3.7 \mathrm{Ga}-380 \mathrm{Ma}$. The paper provides a correlation of supercontinental cycles, which reflects the genesis of complex deposits in large igneous provinces (LIPs) and a breakup of supercontinents during the Earth's evolution.
\end{abstract}

Key words: $\mathrm{U}-\mathrm{Pb}$, zircon, baddeleyite, $\mathrm{T}_{\mathrm{DM}}, \varepsilon^{\mathrm{Nd}}, \mathrm{I}_{\mathrm{Sr}}$ ore deposits, $\mathrm{He}^{3} / \mathrm{He}^{4}$.

Кольский центр коллективного пользования (ЦКП) геохронологических и геохимических исследований был создан в 2000 году (приказ директора ГИ КНЦ РАН, акдемика РАН Митрофанова Ф.П.) на базе уникального семиканального масс-спектрометра Finnigan-MAT 262, оснащенного квадрупольной установкой RPQ (для измерений нано и пико концентраций радиоизотопов (U, Рb и др.). Кольский ЦКП включает в основном сепарационную группу для выделения акцессорных (циркон, рутил, титанит, монацит, бадделеит-впервые в России) для изотопного U-Pb датирования, породообразующих (оливин, ортопироксен, плагиоклаз и сульфидных ЭПГ содержащих минералов - впервые в России) для $\mathrm{Sm}-\mathrm{Nd}, \mathrm{Rb}-\mathrm{Sr}$ и $\mathrm{He}^{3} / \mathrm{He}^{4}$ исследований. На балансе центра находятся 2 твердофазных (МИ-1201Т) и 2 газовых (МИ1201Г) масс-спектрометра украинского производства (г. Сумы) и 4 чистые комнаты - модули для U-Pb, Sm-Nd и Rb-Sr химических процедур для разложения первичных проб пород и минералов на изотопно-геохимические исследования с низкими (нано и пико) холостыми загрязнениями. 
Главными достижениями Кольского ЦКП являются комплексные $\mathrm{U}-\mathrm{Pb}, \mathrm{Sm}-\mathrm{Nd}, \mathrm{Rb}-\mathrm{Sr}, \mathrm{He}^{3}$ / $\mathrm{He}^{4}\left(\mathrm{REE}, \mathrm{T}_{\mathrm{DM}}, \varepsilon \mathrm{Nd}, \mathrm{I}_{\mathrm{Sr}}\right.$, и др.) изучения пород и месторождений стратегических полезных ископаемых (Cu-Ni, Cr-Ti-V, ЭПГ и др.), а также пород фундамента - континентальной и океанической коры, на которых формируются месторождения.

Древнейшие породы континентальной коры продатированы U-Pb методом по циркону, выделенному из высокоглиноземистых гнейсов Центрально-Кольского мегаблока (рис. 1 a). Ядра циркона были изучены SHRIMP-II методом во ВСЕГЕИ (Санкт-Петербург) и отразили возраст в 3.7 млрд. лет (рис. 1 б), который является древнейшим в восточной части Фенноскандинавского щита и близким 3.73 млрд. лет (Huhma et al., 2018) возрасту циркону из трондьемитов Сурия (Финляндия), продатированому на масс-спектрометре NordSIM (Швеция).
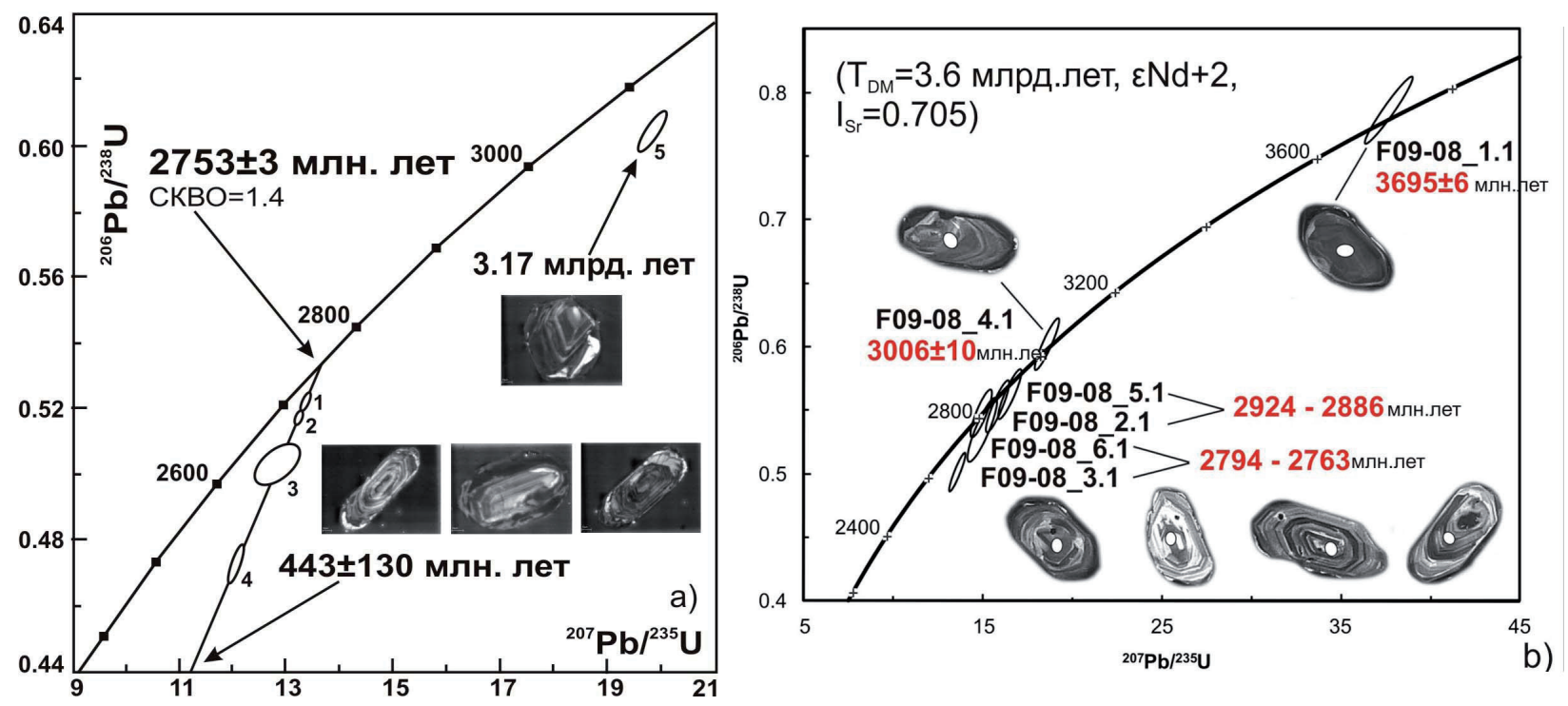

Рис. 1. Изотопная U-Pb диаграмма с конкордией для циркона из высокоглинозёмистых серых гнейсов Центрально-Кольского мегаблока (a), диаграмма SHRIMP-II данных для циркона Центрально-Кольского мегаблока (b).

Fig. 1. U-Pb isotope diagram with concordia for zircon from high-alumina gray gneisses of the Central Kola megablock (a), SHRIMP-II data diagram for zircon from the Central Kola megablock (b) (Bayanova et al., 2016).

На породах этой континентальной коры были образованы почти все неоархейские месторождения: золоторудные Оленинское и Няльм 1 (рис. 2 a, b), железорудные (Оленегорское), Ti-Mag (Цагинское) и карбонатитовое Сиилинъярви, Финляндия (рис. $3 \mathrm{a}, \mathrm{b}, \mathrm{c}$ ). Можно отметить, что главные возрастные рубежи формирования были продатированы U-Pb методом по бадделеиту (pис. 4 a, b, c).

Месторождения стратегических полезных ископаемых Мончегорского, Федорово-Панского и Имандровского рудных районов также образованы на породах континентальной коры эоархейпалеоархейского возраста. Все главные фазы формирования месторождений были продатированы $\mathrm{U}-\mathrm{Pb}$ методом по бадделеиту (рис. 4 a, b, c).

Можно отметить, что бадделеит (Bayanova, 2006; Corfu et al., 2011) является более надёжным геохронометром по сравнению с цирконом, поэтому главные $\mathrm{Pt}-\mathrm{Pd}$ и $\mathrm{Cu}-\mathrm{Ni}$ месторождения мира Бушвельд (Mungall et al., 2016) и Стиллуотер (Wall et al., 2018) были продатированы с использованием этого минерала.

Месторождения стратегических полезных ископаемых $\mathrm{Cr}, \mathrm{Cu}-\mathrm{Ni}$ и $\mathrm{Pt}-\mathrm{Pd}$ Падостундровской, Печенгской и Кандалкшско-Колвицкой зоны были сформированы на коре океанического типа (рис. 5 a, b, с), согласно геологическим (Минц и др., 2017) и изотопно-геохимическим данным.

Комплексные REE апатит-нефелиновые и другие месторождения палеозоя были сформированы на коре переходного типа: частично на океанической и частично на континентальной по данным $\mathrm{Sm}-\mathrm{Nd}$ и $\mathrm{Rb}-\mathrm{Sr}$ изотопных систем (рис. 6 a, b, c). 

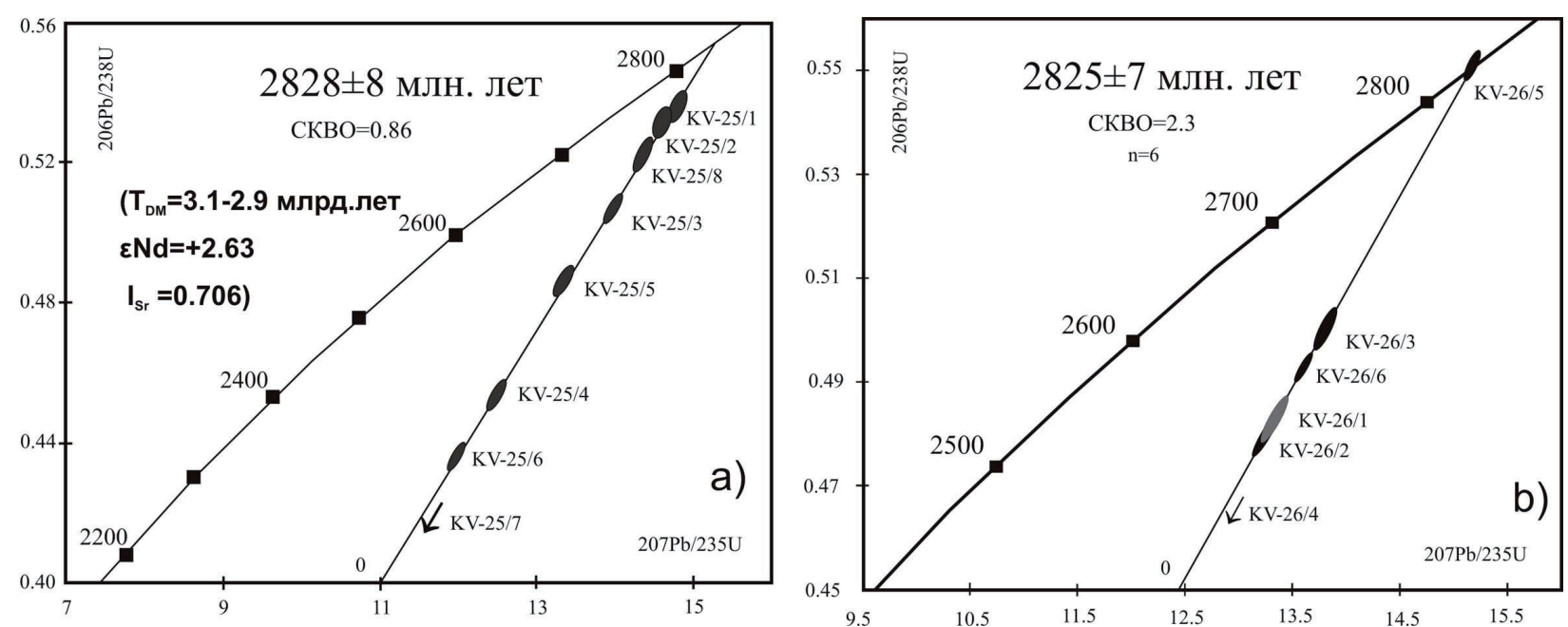

Рис. 2. Изотопные U-Pb диаграммы с конкордией для циркона из кварцевых порфиров рудопроявления Оленинское (а) и для гранодиорит-порфиров рудопроявления Няльм-1 (b) (Кудряшов и др., 2015).

Fig. 2. U-Pb isotope diagrams with concordia for zircons from the quartz porphyries of the Oleninskoe ore occurrence (a) and for granodiorite porphyries of the Nyalm-1 ore occurrence (b) (Kudryashov et al., 2015).
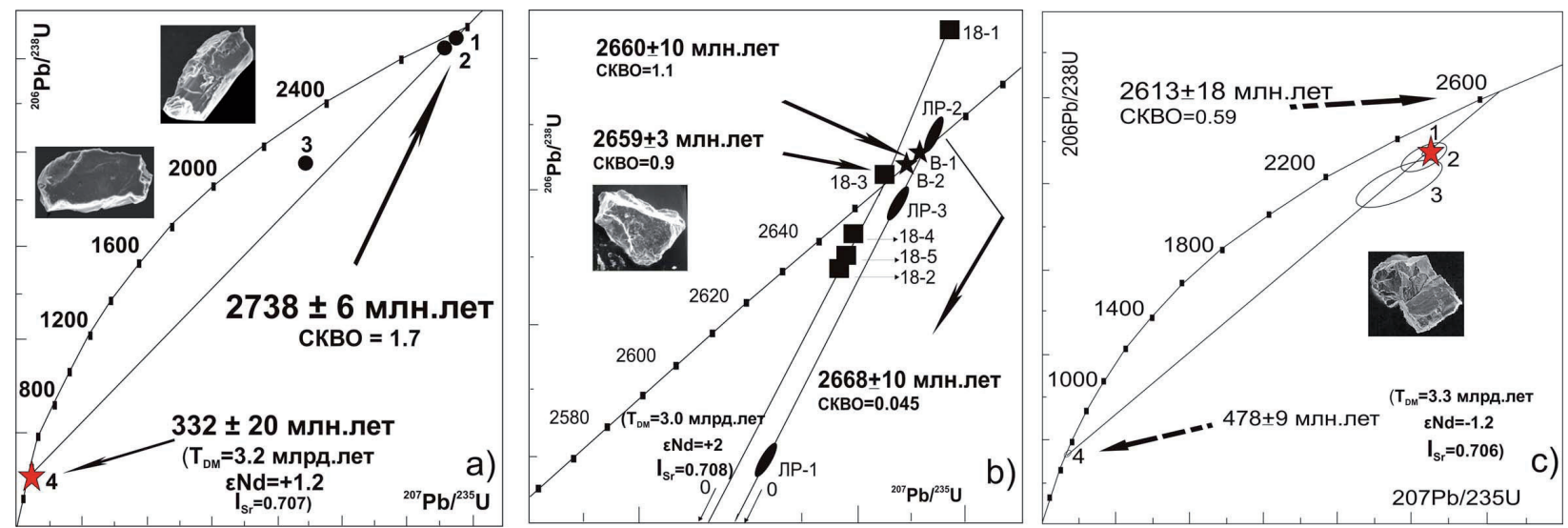

Рис. 3. U-Pb диаграммы для циркона и бадделеита из базитовой дайки Кировогорского месторождения (а); из пород Цагинского массива (b); из пород массива Силлинъярви (c).

Fig. 3. U-Pb diagram for zircon and baddeleyite from the basic dyke of the Kirovogorsky deposit (a); from rocks of the Tsaginsky massif (b); from the rocks of the Sillinjärvi massif (c) (Bayanova, 2006).
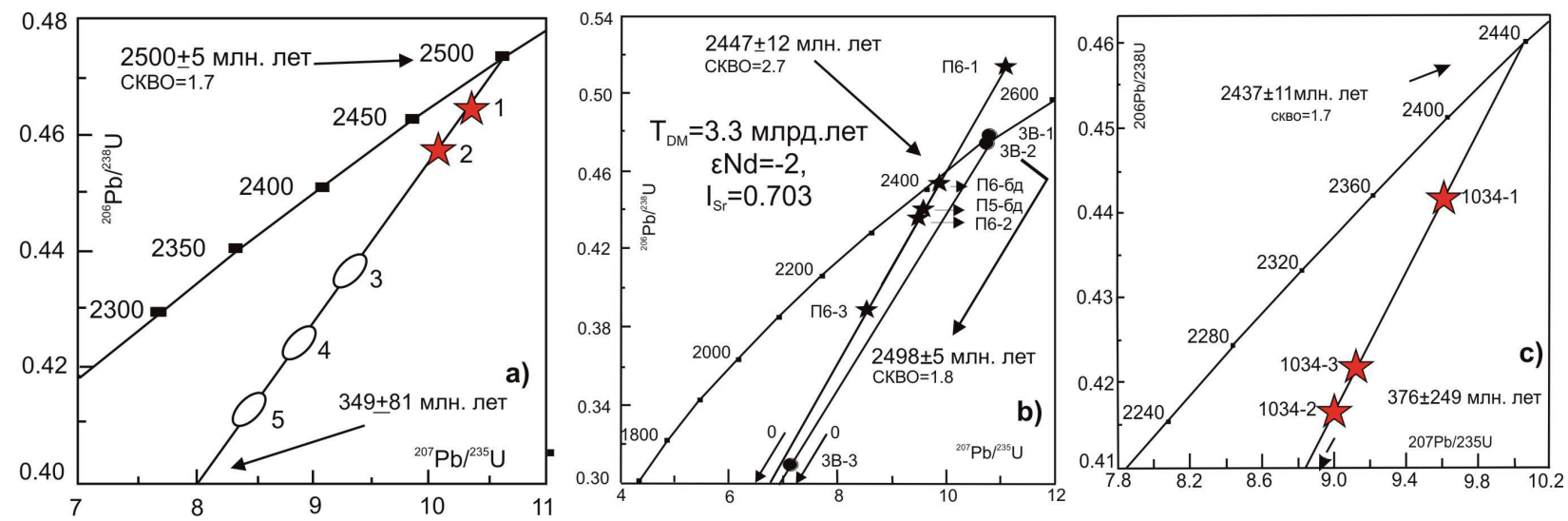

Рис. 4. Изотопные U-Pb диаграммы с конкордией для циркона и бадделеита из $\mathrm{Cu}-\mathrm{Ni}$ - месторождения Нюд (a) Мончегорского плутона; Pt-Pd месторождений Фёдорово-Панского массива (b), Cr-Ti-V месторождений Имандровского лополита (с) (Баянова, 2006).

Fig. 4. U-Pb isotope diagrams with concordia for zircon and baddeleyite from the Cu-Ni deposit Nud (a) of Monchegorsk pluton; Pt-Pd deposits of the Fedorovo-Pansky massif (b), Cr-Ti-V deposits of the Imandra lopolith (c) (Bayanova, 2006). 

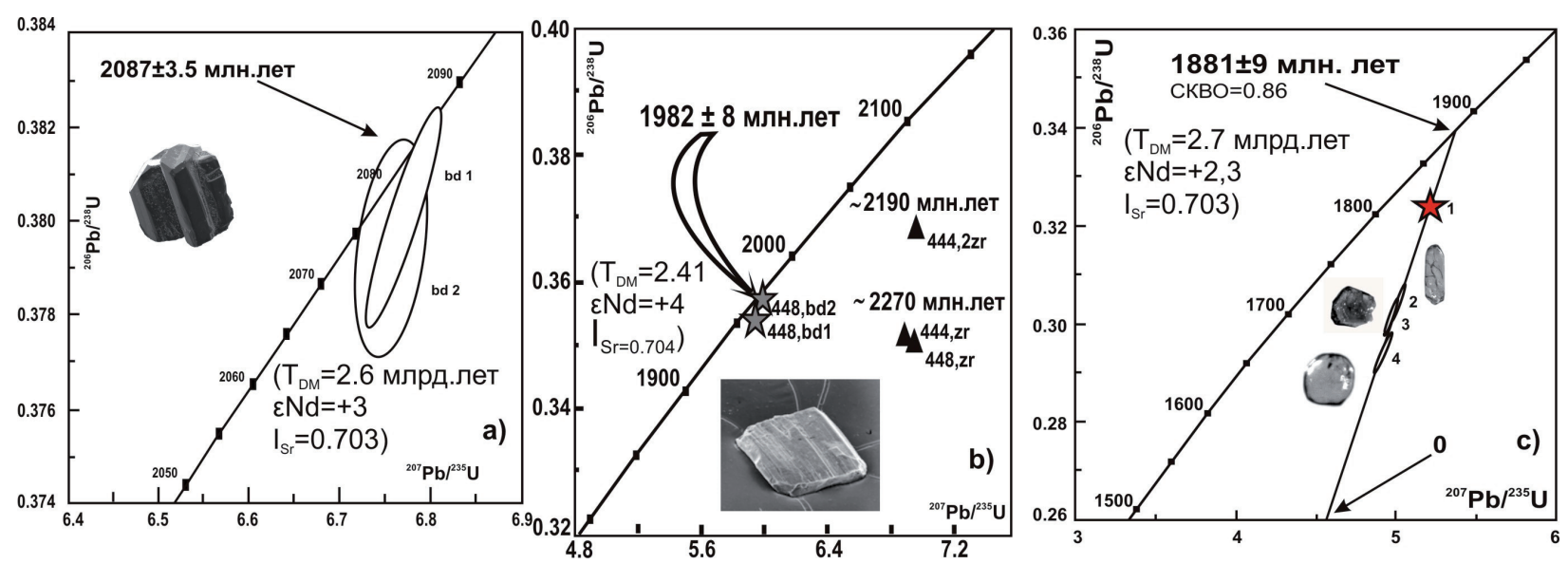

Рис. 5. Изотопные U-Pb диаграммы с конкордией по бадделеиту из метагаббро Сr Падостундровского месторождения (a), бадделеита и циркона из $\mathrm{Cu}-\mathrm{Ni}$ месторождения Печенги (b), бадделеита и циркона из Ti-Mag Колвицкого месторождения (c).

Fig. 5. U-Pb isotope diagrams with concordia for baddeleyite metagabbro of the Cr Padostundra deposit (a); baddeleyite and zircon from the $\mathrm{Cu}-\mathrm{Ni}$ Pechenga deposit (b), baddeleyite and zircon from the Ti-Mag Kolvitsa deposit (c).

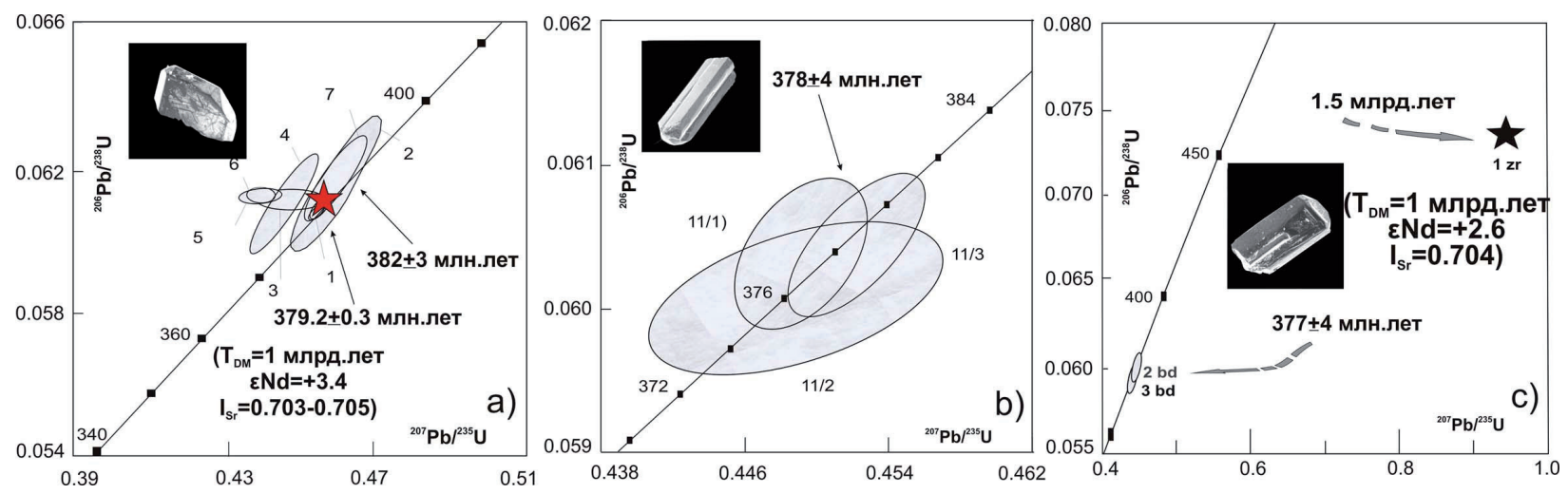

Рис. 6. Изотопные данные U-Pb для бадделеита из фоскоритовой руды, Ковдор (a), бадделеита из карбонатита Себльявра (b) и циркона (1) из пироксенита и бадделеита (2-3) из позднего карбонатита Вуориярви (c) (Баянова, 2006).

Fig. 6. Isotope U-Pb data on baddeleyite from foscorite ore, Kovdor (a), baddeleyite from carbonatite of Sebljavr (b) and zircon xenocryst (1) from pyroxenite and baddeleyite (2-3) from the late carbonatite of Vuorijarvi (c) (Bayanova, 2006).

Таким образом, можно отметить, что поскольку месторождения образуются в обширных мантийно-плюмовых изверженных провинциях (LIP) по данным (Arndt, 2013; Mitrofanov et al., 2013; Ernst, 2014, Yang et al., 2016 и др.), можно сделать предположение об их формировании в связи с распадом суперконтинентов в истории развития Земли.

Все исследования посвящены памяти выдающихся ученых мира - Д. Вассербурга (1927-2016 гг. США), Т. Кроу (1937-2008 гг. Канада), Ф.П. Митрофанова (1935-2014), Е.В. Бибиковой (1934-2016) и Н.П. Лаверову (1930-2016).

Научные исследования выполнены в рамках темы НИР ГИ КНЦ РАН № 0226-2019-0053, проектов РФФИ 18-35-00246, 18-35-00152, 18-05-70082 и программы Президиума РАН 1.48.

\section{Литература}

1. Кудряшов Н.М., Калинин А.А., Лялина Л.М., Серов П.А., Елизаров Д.В. Геохронологические и изотопногеохимические характеристики пород, вмещающих рудопроявления золота архейского зеленокаменного пояса Колмозеро-Воронья (Кольский регион) // Литосфера. 2015. № 6. С. 83-100.

2. Минц М.В., Соколова Е.Ю., Глазнев В.Н., рабочая группа ЛАДОГА. Объемная модель глубинного строения Свекофеннского аккреционного орогена (Финляндия, Россия): синтез данных геологического карти- 


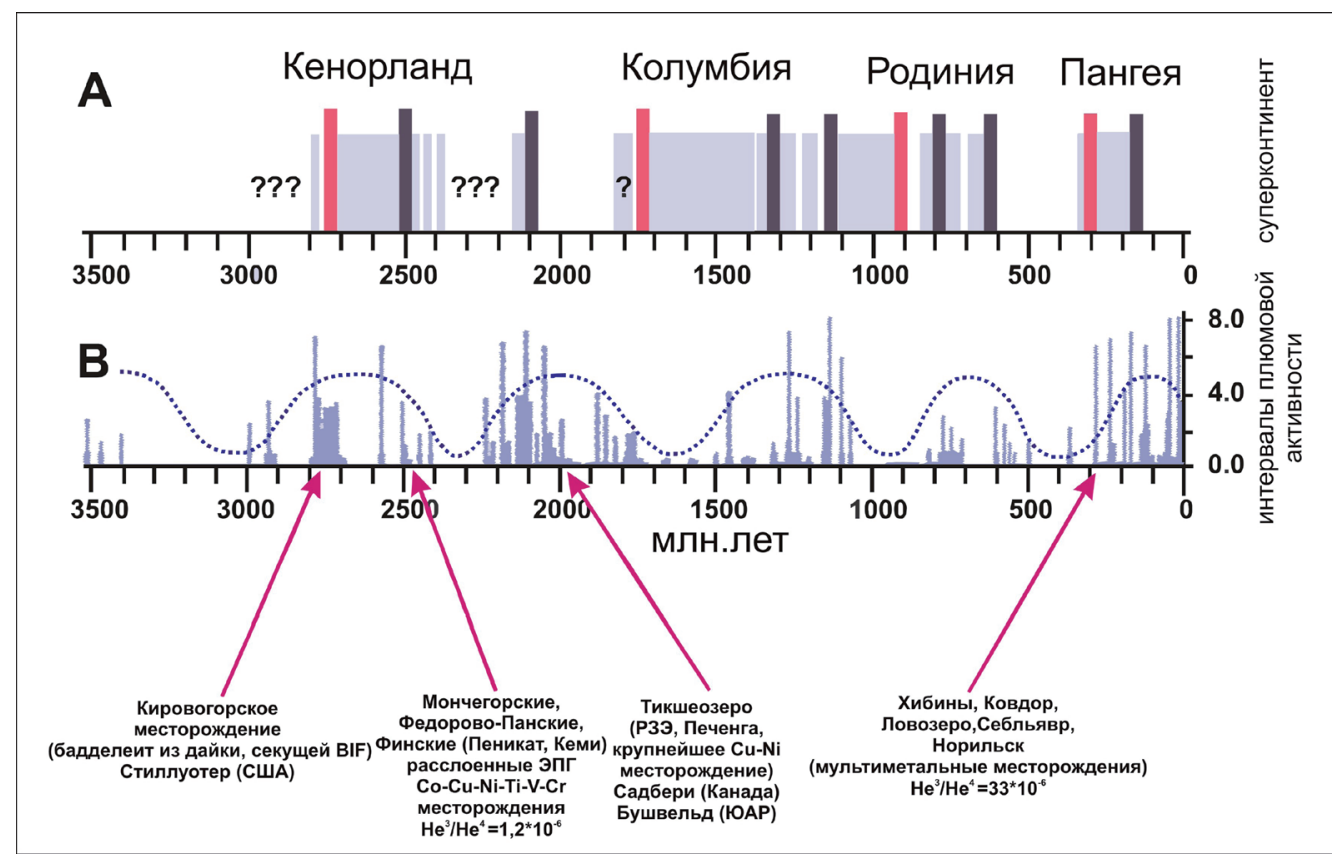

Рис 7 Корреляция (Lubnina, 2009) суперконтинентальных циклов (А) с периодом 750-900 млн и активности мантийных плюмов (B).

Fig. 7 Correlation (Lubnina, 2009) of supercontinental cycles (A) with a period of 750-900 Ma and activity of mantle plumes (B).

рования, сейсмопрофилирования, магнитотеллурики и Материалы научной конференции и путеводитель научных экскурсий. Геодинамика раннего докембрия: сходства и различия с фанерозоем. Петрозаводск: Карельский научный центр РАН, 2017. С. 179-184.

3. Arndt N. The Lithospheric Mantle Plays No Active Role in the Formation of Orthomagmatic Ore Deposits // Economic Geology. 2013. V. 108. P. 1953-1970.

4. Bayanova T.B. Baddeleyite: A Promising Geochronometer for Alkaline and Basic Magmatism // Petrology, 2006. V. 14. N. 2. P. 187-200.

5. Bayanova T.B., Kunakkuzin E.L., Serov P.A., Fedotov D.A., Borisenko E.S., Elizarov D.V. and Larionov A.V. . Precise U-Pb (ID-TIMS) and SHRIMP-II ages on single zircon and Nd-Sr signatures from Achaean TTG and high aluminum gneisses on the Fennoscandian Shield / 32nd Nordic Geological Winter Meeting, Helsinki, Finland, 13-15 January 2016. Abs. Spec. V. P. 172.

6. Corfu F., Bayanova T., Shchiptsov V., Frantz N. A U-Pb ID-TIMS age of the Tiksheozero carbonatite: expression of 2.0 Ga alkaline magmatism in Karelia, Russia // Central European Journal of Geosciences, 2011. P. $302-308$.

7. Ernst, R. E. Large Igneous Provinces. Cambridge University Press, Cambridge.2014. P. 666.

8. Huhma H., Hanski E., Kontinen A., Vuollo J., Mänttäri I., Lahaye Y. Sm-Nd and U-Pb isotope geochemistry of the Palaeoproterozoic mafic magmatism in eastern and northern Finland // Bulletin 405 Monograph. 2018.

9. Lubnina N.V. East-European craton from neoarhaean to paleozoic time based on paleomagnetic data// Manuscript of doctoral dissertation. Moscow: MSU, 2009. 40 p.

10. Mitrofanov F.P, Bayanova T.B, Korchagin A.Y. et al. East Scandinavian and Noril'sk Plume Mafic Large Igneous Provinces of Pd-Pt Ores: Geological and Metallogenic Comparison // Geology of Ore Deposits, 2013. V. 55. N. 5. P. 305-319.

11. Mungall J.E, Kamo S.L., McQuade S.. U-Pb geochronology documents out-of-sequence emplacement of ultramafic layers in the Bushveld Igneous Complex of South Africa // NATURE COMMUNICATIONS. 2016. 7:13385.DOI: 10.1038/ncomms1338.

12. Wall C.J., Scoates J.S., Weis D., Friedman R.M., Amini M., Meurer W.P. The Stillwater Complex: Integrating Zircon Geochronological and Geochemical Constraints on the Age, Emplacement History and Crystallization of a Large, Open-System Layered Intrusion // Journal of Petrology. 2018. V. 59. N. 1. P. 153-190. doi: 10.1093/ petrology/egy024.

13. Yang S-H., Hanski E., Li C., Maier W. D., Huhma H., Mokrushin A. V., Latypov R., Lahaye Y., O’Brien H., Qu W-J. Mantle source of the 2.44-2.50 Ga mantle plume-related magmatism in the Fennoscandian Shield: evidence from $\mathrm{Os}, \mathrm{Nd}$ and $\mathrm{Sr}$ isotope compositions of the Monchepluton and Kemi intrusions // Mineralium Deposita, 2016. V. 51. P. 1055-1073. 